\title{
Microbial kinetic analysis of a hybrid UASB reactor
}

\author{
Oktem Y.A.* \\ Istanbul University-Cerrahpasa, Faculty of Engineering, Department of Environmental Engineering, 34320, Turkey \\ Received: 25/06/2019, Accepted: 24/09/2020, Available online: 13/10/2020 \\ *to whom all correspondence should be addressed: e-mail: oktemy@istanbul.edu.tr
} https://doi.org/10.30955/gnj.003171

\section{Graphical abstract}

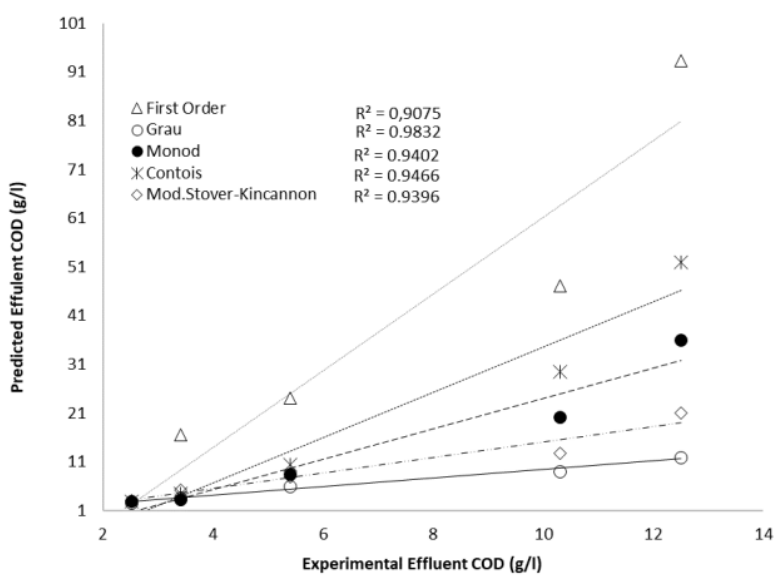

\section{Abstract}

Microbial kinetics of a hybrid upflow anaerobic sludge blanket (UASB) reactor were investigated when treating chemical synthesis-based pharmaceutical wastewater. Mathematical kinetics models have been tested with strong wastewater to reveal the relationship between substrate utilization rate and microbial population dynamics, depending on the hydraulic structure of the reactor. The data were collected for use in these models by operating at mesophilic temperature $\left(37 \pm 1^{\circ} \mathrm{C}\right), \mathrm{pH} 6.8-7.2$, at different HRT (3-0.17 days) at high OLR values from hybrid UASB. Monod, First-order, Grau second-order, Modified Stover-Kincannon, kinetic models were applied to the hybrid reactor. Grau second-order model and Modified Stover-Kincannon were found to be the most appropriate models for the hybrid UASB $\left(R^{2}=0.99\right)$ and offers the best description of the process. The substrate removal rate constant $\left(k_{2 s}\right)$ was found to be $3.43 \mathrm{~d}^{-1}$ for Grau ve maximum substrate consumption rate $\left(R_{\max }\right) 1.016 \mathrm{~g} \mathrm{I}^{-1}$-day for Modified Stover-Kincannon.

Keywords: Hybrid UASB, microbial kinetic, anaerobic, Grau-second order, modified Stover Kincannon.

\section{Introduction}

Chemical synthesis-based pharmaceutical wastewater has a high chemical oxygen demand (COD) and a variable concentration of salts. Many researchers have tried different conventional methods for wastewater treatment such as biological oxidation, physico-chemical process; carbon bed adsorption, coagulation/flocculation, membrane separation, electrochemical treatment and oxidation etc. (Sakumoto and Miyata, 1984; Shubham et al., 2020). But the reduction in the level of toxicity using these methods have been not meet the environmental regulations especially for the complex effluents (Chandak et al., 2020). High rate reactors such as, upflow anaerobic sludge blanket (UASB) reactor or anaerobic filter (AF) have been successfully applied to the treatment of a wide variety of industrial wastewaters; pulp-paper liquor(Ahn and Forster, 2002), spent sulphide liquors (Jantsch et al., 2002), swine wastewater (Perla et al., 2020), chemical synthesis-based pharmaceutical wastewater (Oktem et al., 2007), oilfield wastewater (Zhang, 2020), food industry wastewaters (Berardino et al., 2000; Tsui et al., 2020) and strong industrial wastewaters (Fernândez et al., 2001; Shivayogimath and Ramanujam, 1999). The fundamental way to maintain optimum operating conditions of anaerobic digestion systems is to have a well understand the dynamic behaviours of the process. Therefore, a welldefined mathematical model of the process can be very useful from observing and estimating state of the process (Senturk et al., 2013). Addition, mathematical models based on process kinetics can be used to understand the underlying biological and transport mechanisms also (Acharya et al., 2011). Using kinetic model is a generally accepted approach in showing the system performance. Therefore, kinetic models can be used to find treatment performance of anaerobic digesters without real time operated. Process kinetics is essential tool for the improvement of treatment efficiency of biologically systems. It provides a rational basis for process analysis, control, and design, as well as relating with operational and environmental factors affecting substrate utilization rates (Alavi et al., 2016; Andualem et al., 2017; Feng et al., 2020; Mengcheng, 2020; Saberia et al., 2017). microbial kinetic studies reported in the literature have been for various types of reactors and wastewaters (Abtahi et al., 2017; Tomar and Gupta, 2016; Zhou et al., 2017). However, there is still lack of information in literature concerning substrate utilization rate, mo population dynamic and treatment efficiency at hybrid UASB reactors. OLR effect on the processes of substrate utilization, population dynamics, 
etc. of microorganisms in hybrid UASB are of great importance. In this study, therefore, biokinetic models were tested at different OLR and HRT's at the hybrid UASB reactor.

\section{Materials and methods}

\subsection{Hybrid UASB reactor}

The lab-scale experiment was performed to assess the digestion ability of UASB system at different operating conditions. Reactor was designed and operated as an upflow anaerobic reactor with batch feeds. The reactor was made of glass that is sealed, has a working volume of 4 litre, and connected to the gas collecting bottle with a rubber tube. The environment and operating conditions of the reactor have been determined in accordance with anaerobic mo population. The $\mathrm{pH}$ of the reactor was controlled automatically at 6.8-7.2 by adding $1 \mathrm{~N} \mathrm{NaOH}$ and $1 \mathrm{~N} \mathrm{HCL}$. The top half part of the reactor was filled with polypropylene pall rings (internal diameter, $25 \mathrm{~mm}$; density $70 \mathrm{~kg} \mathrm{~m}^{-3}$, and specific surface area, $206 \mathrm{~m}^{2} \mathrm{~m}^{-3}$ ). The reactor was placed in a water bath where the temperature is $37 \pm 1^{\circ} \mathrm{C}$ using a temperature controller. The temperature in the reactor was adjusted by an external, thermostatically controlled, hot water jacket.

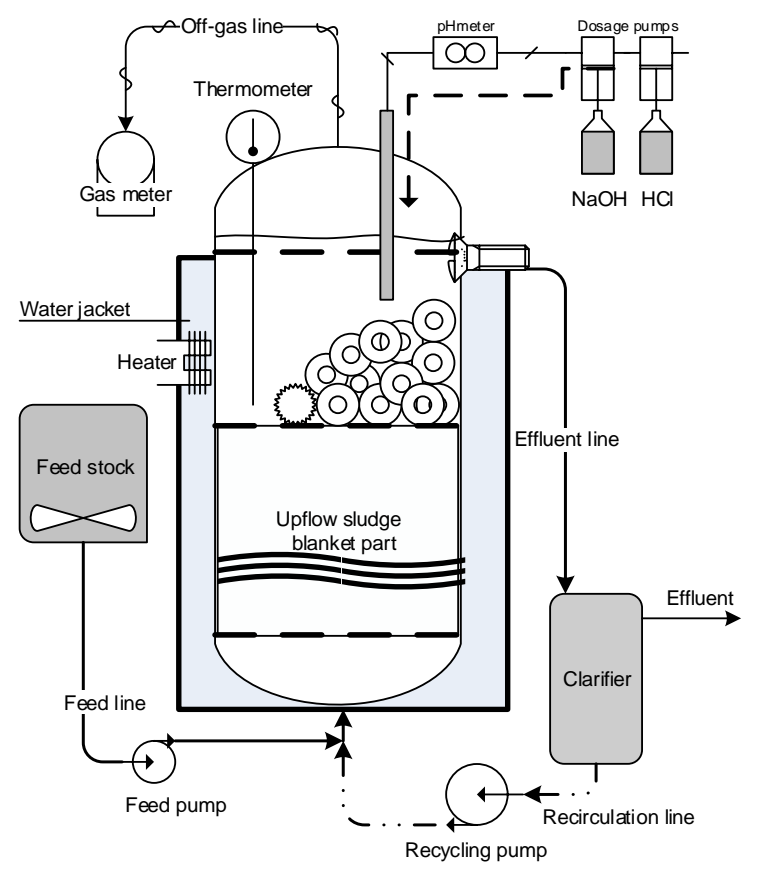

Figure 1. Hybrid UASB reactor (hUASB)

\subsection{Wastewater and seed sludge}

The wastewater was taken from a local chemical synthesisbased pharmaceutical facility. The general characteristics of the wastewater are given in Table 1 . The hybrid reactor was seeded with an inoculation sludge taken from a UASB reactor treating effluents from a local alcohol distillery. The hybrid reactor was seeded inoculation granular sludge taken from the UASB $(20 \% \mathrm{v} / \mathrm{v})$. The reactor was then flushed with nitrogen gas for a period of $15 \mathrm{~min}$ in order to purge gaseous oxygen from inside the reactor.
Table 1. Characteristics of the chemical synthesis-based pharmaceutical wastewater (Oktem, 2004)

\begin{tabular}{cc}
\hline Parameter & Range \\
\hline $\mathrm{pH}^{*}$ & $6.9-7.6$ \\
\hline Total COD $\left(\mathrm{mg} \mathrm{L}^{-1}\right)$ & $15000-51000$ \\
\hline $\mathrm{TSS}\left(\mathrm{mg} \mathrm{L}^{-1}\right)$ & $6360-14900$ \\
\hline $\mathrm{NH}_{3}-\mathrm{N}\left(\mathrm{mg} \mathrm{L}^{-1}\right)$ & $100-120$ \\
\hline $\mathrm{TKN}\left(\mathrm{mg} \mathrm{L}^{-1}\right)$ & $825-910$ \\
\hline $\mathrm{PO}_{4}-\mathrm{P}\left(\mathrm{mg} \mathrm{L}^{-1}\right)$ & $<1$ \\
\hline $\mathrm{C} / \mathrm{N}$ & $18-56(33)$ \\
\hline $\mathrm{BOD}_{5}$ & $3200-35600$ \\
\hline
\end{tabular}

\section{*Unitless}

\subsection{Analytical procedure}

During the operation of the hybrid reactor, routine analyses were carried out determined. Biogas production, $\mathrm{pH}$, alkalinity, volatile fatty acids (VFAs), TS and TVS, $\mathrm{pH}$, total Kjeldahl nitrogen (TKN), ammonia nitrogen $\left(\mathrm{NH}_{3}-\mathrm{N}\right)$, orthophosphate phosphorus $\left(\mathrm{PO}_{4}-\mathrm{P}\right)$, alkalinity, and suspended solids (TS) such as parameters' analysis were carried out in accordance with to Standard Methods (APHA, 2017). Total solids (TS) and total volatile solids (TVS) parameters were used instead of suspended solids (SS) and volatile suspended solids (VSS) due to the granular characteristics of the sludge. The TS concentration of the seed sludge was approximately $100 \mathrm{~g} / \mathrm{l}$ of which about $96 \%$ was TVS (Oktem, 2004). Effluent wastewater samples were centrifuged at $12000 \mathrm{rpm}$, and the soluble chemical oxygen demand (SCOD) concentration of the supernatant was measured. Chemical oxygen demand (COD) (5220 D-Closed Reflux, Colorimetric Method), 5-day biological oxygen demand (BOD-5210 B. 5-Day BOD Test) were analyzed according to Standard Methods (APHA, 2017). To determine Volatile Fatty Acids (VFAs), samples was centrifuged at $9900 \mathrm{rpm}$ and $4^{\circ} \mathrm{C}$ for 20 min after well shaken. Supernatant was filtered through filter membrane filter, $0.22 \mu_{\mathrm{m}}$ pore size $47 \mathrm{~mm}$ diameter. The sample was used for analysis of soluble substances. 3\% phosphoric acid solution was added to the filtrate to avoid degradation at a volume ratio of 1:9 for the analysis of volatile fatty acids (VFAs). Short Chain Fatty Acids (SCFA C2-C6) were measured using a HP Model 5890 Series II Gas Chromatograph (GC) (HP FFAP Column, 10 m/530 mm/1 $\mathrm{mm}$ ) with used nitrogen as carrier.

\subsection{Reactor operation}

The $\mathrm{C} / \mathrm{N}$ ratio, among other factors, should be set out at hold safety range to ensure process stability. The appropriate $\mathrm{C} / \mathrm{N}$ ratio for effective metabolic processes of anaerobic microbial groups is in the 20-30 range (Athanasoulia et al., 2012). The range for chemical synthesis-based pharmaceutical wastewater has been determined as 33. Solids retention (SRT) was achieved through control of the upflow velocity (UV) in the reactor, which was effected by control of the effluent recirculation flow rate. As stated in the previous study, the upflow speed was chosen as $0.5 \mathrm{~m} / \mathrm{h}$ to ensure better contact of sludge and wastewater (Oktem et al., 2007; Yue et al., 2020). Macro nutrients (nitrogen and phosphorus as $\left(\mathrm{NH}_{2}\right)_{2} \mathrm{CO}$ and $\mathrm{KH}_{2} \mathrm{PO}_{4}$, respectively) were added to the nutrient balance in the feed solution according to the C:N:P ratio of 400:5:1. 
The results obtained for steady state conditions during reactor operation at five different HRTs was used at kinetic models. The ratio of $\mathrm{BOD}_{5} / \mathrm{COD}$ was determined that is almost same other reported studies with pharma wastewaters (Boroski et al., 2009; Chen et al., 2011; Farhadi et al., 2012). Special feeding strategy was used in order to obtain a better reactor performance and allow microorganisms for acclimate to wastewater. It was recommended reported studies that start-up periods for treatment of pharmaceutical wastewater should be carried out with gradual replacement of readily degradable substrate. Therefore, in many experimental studies glucose was commonly used (Stronach et al., 1986). The hybrid reactor was initially fed with glucose at an OLR of 5.8-6.2 kg COD $\mathrm{m}^{-3} \mathrm{~d}^{-1}$ with a hydraulic retention time (HRT) of 1-3 days. Then, with wastewater, up to $104.7 \mathrm{~kg} \mathrm{COD} \mathrm{m}^{-3} \mathrm{~d}^{-1}$ load was reached, in this process, HRT was between 0.17 3 days. For the alkalinity support to the reactor was added $\mathrm{NaHCO}_{3}$

\subsection{Kinetic models}

Modeling methods are useful tools for describing and predicting the performance of anaerobic treatment systems. There are various models for predicting effluent substrate concentrations in anaerobic treatment systems, including Monod (Monod, 1949), Contois (Contois, 1959), Grau second-order (Grau, 1975), Grau, and StoverKincannon Modified (Stover and Kincannon, 1982). The input data to all these models should be taken form at steady-state condition of reactor. In a recirculated UASB reactor, the rate of change of biomass and substrate is shown in the following equations ( 1 and 2 ).

$$
\begin{gathered}
V \frac{d_{s}}{d_{t}}=Q S_{0}+Q_{r} S-\frac{\mu \cdot X}{Y} \\
V \frac{d_{x}}{d_{t}}=Q X_{0}+Q_{r} X_{e}+\mu X-k_{d} X
\end{gathered}
$$

where $X_{0}, X$ and $X e$ are the concentrations of biomass in the feed, reactor and effluent respectively ( $\mathrm{g} \mathrm{VSS} \mathrm{I}^{-1}$ ); $Q$ is the inflow rate $\left(I\right.$ day $\left.^{-1}\right) ; V$ is the reactor volume $(I) ; \mu$ is the specific growth rate $\left(\mathrm{d}^{-1}\right) ; K \mathrm{~d}$ is the death rate constant $\left(d^{-1}\right) ; S_{0}$ and $S$ are the substrate concentrations in the feed and effluent ( $\mathrm{g} \mathrm{COD} \mathrm{l}^{-1}$ ); $Y$ is the yield coefficient ( $\mathrm{g}$ VSS $\mathrm{g}$ $\left.C O D^{-1}\right)$. The ratio of the total biomass in the reactor to biomass wasted per given time represent the average time called as mean cell-residence time $(\Theta c)$ and calculated from the equation (3) for AHR.

$$
\theta_{C}=\frac{V \cdot X}{Q \cdot X_{e}}
$$

\subsection{Monod model}

The relationship between the specific growth rate and the rate limiting substrate concentration can be expressed by the Monod (5) and Contois (6). In the Monod model, the concentration changes rate of substrate is expressed by equation 1 . Using equation 3 , the concentration of the substrate at the effluent (4) can be calculated.

$$
\mu=\frac{\mu_{m} S}{K_{s}+S}
$$

$$
\mu=\frac{\mu_{m} S}{\beta \cdot X+S}
$$

If it is assumed that the concentration of biomass in the influent can be neglected at steady-state conditions and $\operatorname{HRT}\left(\Theta_{H}\right)$ is defined as the volume of the reactor divided by the flow rate of the influent, following equations can be obtained by substituting and rearranging equations ( 3 ) and (4) into equations (1) and (2);

$$
\begin{gathered}
\mu=\frac{1}{\theta_{c}}+K_{d} \\
\mu=\frac{1}{\theta_{c}}=\frac{1}{\theta}=\frac{\mu_{m} S}{\left(K_{s}+S\right)}-k_{d}
\end{gathered}
$$

The kinetic parameters $Y$ and $K_{d}$ for Monod model can be obtained equations (8) by rearranging equations and plotting Figure 2 as shown below:

$$
\frac{S_{0}-S}{\theta H \cdot X}=\frac{1}{Y} \cdot \frac{1}{\theta c}+\frac{K_{d}}{Y}
$$

The values of $\mu$ max and $K_{s}$ were determined from Figure 3 by plotting equation (9), which was derived by rearranging equation (7).

$$
\frac{\theta c}{1+\theta c \cdot k_{d}}=\frac{K_{S}}{\mu_{\max }} \cdot \frac{1}{S}+\frac{1}{\mu_{\max }}
$$

\subsection{Grau second-order kinetic model}

The general expression for Grau second-order kinetics is given as follows (10), and the prediction of the substrate concentration at the effluent is given in equation 11 .

$$
\begin{gathered}
-\frac{d_{s}}{d_{t}}=k_{2(S)} \cdot X\left(\frac{S}{S_{0}}\right)^{2} \\
S=S_{0}\left(1-\frac{\theta}{a+b \theta}\right)
\end{gathered}
$$

where, $\mathrm{k}_{2}(\mathrm{~s})$ : substrate removal rate constants. If equation 11 is integrated and linearized, then equation 12 will be obtained,

$$
\frac{S_{0} \theta}{S_{0}-S}=\theta+\frac{S_{0}}{k_{2(S)} \cdot X}
$$

Here, $\theta$ is the hydraulic retention time. If the second part of the equation is accepted as constant and first part of the equation is the substrate removal efficiency that will be obtained.

$$
\begin{gathered}
\frac{S_{0} \theta}{S_{0}-S}=a+b \theta \\
\frac{\theta}{E}=a+b \theta
\end{gathered}
$$

\subsection{Contois model}

By substituting equation (5) instead of the Monod equation into equations (2) and (15) can be obtained:

$$
\mu=\frac{1}{\theta_{c}}+k_{d}
$$




$$
\frac{\theta_{c}}{1+\theta_{c} \cdot k_{d}}=\frac{\beta}{\mu_{m}} \cdot \frac{X}{S}+\frac{1}{\mu_{m}}
$$

If equation 16 is arranged, $b$ and $\mu_{m}$ are obtained from Figure 7 and the reactor effluent substrate concentration estimate can be expressed by equation (17).

$$
S=\frac{\beta X\left(1+k_{d} \theta_{c}\right)}{\mu_{m} \theta_{c}-\left(1+k_{d} \theta_{c}\right)}
$$

\subsection{Modified Stover Kincanon model}

Stover-Kincannon model has been used successfully various wastewater types in specially attached growth reactors (Faridnasr et al., 2016; Kordkandi and Berardi, 2015; Noroozi et al., 2014; Wang et al., 2015). The M Stover - Kincannon model, developed for use in biofilm reactors, has yielded successful results in studies (Sandhya and Swaminathan, 2006). That model recognizes that based on mono-molecular kinetics, substrate utilization rate and organic matter loading rate can be correlated. Substrate removal can be shown in the following two forms.

$$
\begin{gathered}
\frac{d_{S}}{d_{t}}=\frac{Q\left(S_{0}-S\right)}{V} \\
\frac{d S}{d t}=\frac{U_{m}\left({ }^{Q S_{0}} / V\right)}{k_{2}+Q S_{0} / V}
\end{gathered}
$$

This equation can be linearized in the following form:

$$
\left(\frac{d S}{d t}\right)^{-1}=\frac{V}{Q\left(S_{0}-S\right)}=\frac{k_{B} V}{R_{\max } Q S_{0}}+\frac{1}{R_{\max }}
$$

Where $\mathrm{dS} / \mathrm{dt}$ is the substrate removal rate $\left(\mathrm{g} \mathrm{L}^{-1} \mathrm{~d}^{-1}\right), R_{\max }$ is the maximum utilization rate constant $\left(\mathrm{g} \mathrm{L}^{-1} \mathrm{~d}^{-1}\right), K_{B}$ is the saturation value constant $\left(\mathrm{g} \mathrm{L}^{-1} \mathrm{~d}^{-1}\right), Q$ is the flow rate $\left(\mathrm{L} \mathrm{d}^{-}\right.$ $\left.{ }^{1}\right)$ and $V$ is the effective volume of reactor (L). Since $d S / d t$ approaches $R_{\max }$ as the organic loading rate, $\mathrm{qS} / \mathrm{V}$ approaches infinity. Then, by this equation, equation 33 is obtained to predict the effluent substrate concentration of the reactor.

\begin{tabular}{|c|c|c|c|c|c|}
\hline Experimental setup & 1 & 2 & 3 & 4 & 5 \\
\hline Feed $\left(\right.$ ( day $\left.{ }^{-1}\right)$ & 0.0272 & 0.0093 & 0.0047 & 0.0023 & 0.0016 \\
\hline COD Feed $\left(\mathrm{mg} \mathrm{L}^{-1}\right)$ & 15400 & 15430 & 15400 & 15520 & 15225 \\
\hline Total gas yield ( $\mathrm{L} \mathrm{g} \mathrm{COD}^{-1}$-day) & 0.47 & 0.44 & 0.39 & 0.37 & 0.3 \\
\hline Methane (\%) & 80 & 75 & 74 & 75 & 76 \\
\hline Methane Yield (L g COD-1-day) & 0.33 & 0.30 & 0.28 & 0.26 & 0.2 \\
\hline $\operatorname{MLSS}\left(\mathrm{kg} \mathrm{m}^{-3}\right)$ & 12.8 & 16.3 & 21.4 & 22.4 & 22.4 \\
\hline $\operatorname{MLVSS}\left(\mathrm{kg} \mathrm{m}^{-3}\right)$ & 7.53 & 9.32 & 11.90 & 12.70 & 12.90 \\
\hline HRT (day) & 0.17 & 0.5 & 1 & 2 & 3.0 \\
\hline SRT (day) & 28 & 50 & 120 & 310 & 580 \\
\hline OLR (kg COD m-3-day) & 104.76 & 35.98 & 17.99 & 8.99 & 6.03 \\
\hline SSUR (gCOD gVSS-1-day) & 0.120 & 0.412 & 1.057 & 2.294 & 3.615 \\
\hline SUR (gCOD gVSS ${ }^{-1}$-day) & 0.71 & 0.82 & 1.06 & 1.15 & 1.21 \\
\hline COD Removal (\%) & 0.30 & 0.3 & 0.70 & 0.81 & 0.86 \\
\hline
\end{tabular}

$$
S=S_{0} \frac{R_{m}\left(S_{i}\right)}{K_{B}+Q S_{0} / V}
$$

\subsection{First order substrate removal model}

Table 2. Experimental data for determining kinetic constants
The hydrolysis of organic pollutants was described by first order kinetics model. The mass balance equation for the substrate in the anaerobic system can be described as follows:

$$
\frac{d s}{d t}=\frac{Q}{V} \cdot S_{0}-\frac{Q}{V} \cdot S-k_{1} \cdot S
$$

where, $S_{0}$ is substrate concentration in the influent $\left(\mathrm{g} \mathrm{l}^{-1}\right)$ : Se is substrate concentration in the effluent; $Q$ is flow rate of influent to reactor $\left(\mathrm{d}^{-1}\right)$; $\mathrm{V}$ is effective volume of the reactor and $k_{1}$ is first-order kinetic constant (per day). Under steady state conditions, $(d s / d t)=0$ and the above equation can be represented in the following form:

$$
\frac{Q}{V} \cdot\left(S_{0}-S\right)=k_{1} \cdot S
$$

\section{Results and discussion}

This study was carried out to determine of a hybrid UASB reactor' kinetic constants over two months of operation. Table 2 was prepared using experimental results for plot of kinetic models. Biokinetic models including Monod, StoverKincannon, Grau, second-order, etc. were applied to find the most suitable biokinetic model to describe the hybrid reactor.

\subsection{Monod kinetic model}

Five steady state sets of experimental data were used to determine the kinetic parameters. Figure 2 was plotted from equation (8) for determining the values of $Y$ and $K_{d}$ for Monod model and the corresponding values were $0.0095 \mathrm{~g}$ VSS gCOD $^{-1}$ and 0.00115 day $^{-1}$, respectively with high regression coefficient $\left(R^{2}=0.9535\right)$. The decay coefficient value, Kd which was lower than the reported value (Hwang et al., 1992; Singh and Ohja, 2002) might be due to low amount decay of cells. However, The higher yield coefficient obtained in the present investigation could be attributed to relatively larger proportion of biodegradable organic waste (disolved organic subtances) in pharmacetical wastewater. In general, the model parameters are specific to the configuration and operational mode of the reactor. Figure 3 was plotted from equation (9) for determining the values of $\mu$ max and $K s$ for Monod model and the corresponding values were $0.017 \mathrm{~d}^{-1}$ and $16793 \mathrm{mg} \mathrm{COD} \mathrm{l}^{-1}$ ) day, respectively with high regression coefficient $(R 2=0.99)$. 
Table 3 Comparison of kinetic constants in the Modified Stover-Kincannon model

\begin{tabular}{|c|c|c|c|c|}
\hline Types of wastewater & Reactor & $K_{B}\left(\mathrm{~g} \mathrm{COD} \mathrm{I}^{-1}\right)$ & $R_{\max }\left(\mathrm{g} \mathrm{l}^{-1} \mathrm{~d}\right)$ & References \\
\hline $\begin{array}{c}\text { Chemical-based Pharmaceutical } \\
\text { wastewater }\end{array}$ & hUASB & 0.0247 & 1.016 & This study \\
\hline Pharmaceutical wastewater & AHR & 115.66 & 108.69 & (Pandian et al., 2011) \\
\hline Formaldehyde containing wastewater & UAFB & 4.6 & 3.4 & (Priya et al., 2009) \\
\hline Corrugated paper wastewater & $\mathrm{AF}$ & 3.86 & 0.80 & (Ahn and Forster, 2002) \\
\hline Soybean wastewater & $\mathrm{AF}$ & 83.3 & 85.5 & (Yu et al., 1983) \\
\hline Simulated wastewater & MBBR & 9.45 & 8.3 & (Borghei and Hosseiny, 2002) \\
\hline High-strength wastewater & UA-MBR & 34.14 & 33.78 & (Burman and Sinha, 2020) \\
\hline Textile wastewater & UAFR & 45.37 & 31.69 & (Sandhye and Swaminathan, 2006) \\
\hline Textile wastewater & Pilot UASB & 16,12 & 23,17 & (Gnanapragasam et al., 2017) \\
\hline
\end{tabular}

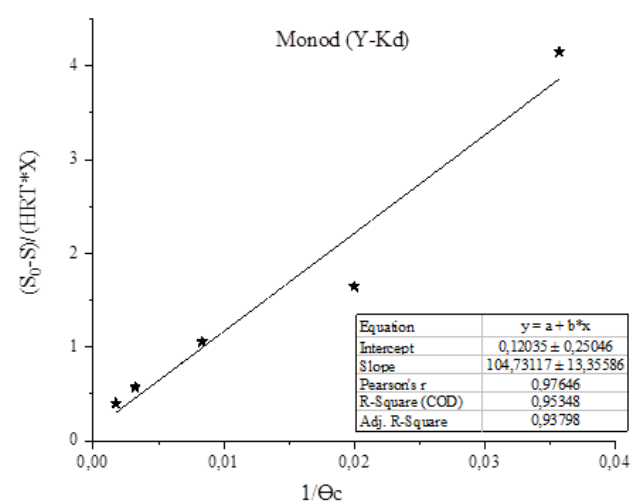

Figure 2. Monod model plot for $(Y)$ and decay rate $\left(K_{d}\right)$ constant

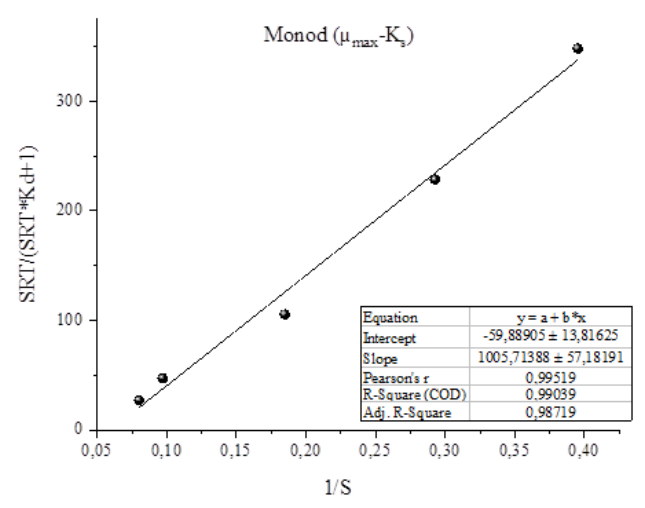

Figure 3. Monod model plot for $\left(\mu_{\max }\right)$ and half saturation constant $\left(K_{S}\right)$

\subsection{Modified Stover-Kicannon model}

The maximum utilization rates increase the reactor efficiency. Stover- Kicannon model suggested that the substrate removal rates $\left(C O D_{r e m}\right)$ were affected by the organic loading rate entering the reactor. Saturation value constant $\left(K_{\mathrm{B}}\right)$ and maximum utilization rate $\left(R_{\max }\right)$ were calculated from Figure 4 as 1,016 $\mathrm{g} \mathrm{COD} \mathrm{l}^{-1}$-d and 0,0247 g COD $~^{-1}-\mathrm{d}$ with high regression coefficient $\left(R^{2}=0.99\right)$. From $R^{2}$ value (Figure 4), the experimental data are found to align with this model. The $R_{\max }$ and $K_{B}$ values obtained in this study were lower than values found by other studies (Table 4).

\subsection{First order substrate removal model}

The value of $k 1$ was obtained from the slope of the line by

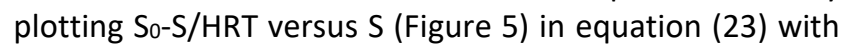
the low regression coefficient of 0.845 . $k_{1}$ is first-order kinetic constant and was calculated from Figure 5 as 2,16 per day.

\subsection{Grau second-order multicomponent substrate removal model}

If equation (10) is integrated and then linearized, equation (14) will be obtained of $a$ and $b$ (dimensionless Grau second-order constant) were calculated from the intercept and slope of the straight line on the graph (Figure 6) as 0.503 and 0.9919 respectively, with high correlation coefficient $\left(R^{2}\right)$ of 0.9916 . The multicomponent Grau second-order substrate removal rate constant $\left(k_{2 s}: 3.43 \mathrm{Id}^{-}\right.$ $\left.{ }^{1}\right)$ was calculated from the equation $a=S o /(k s . X)$ (Table 4). Table 5 shows the constants determined in the previous studies using the Grau second order model. The possible reasons for the differences might be due to variation in reactor configuration, wastewater characteristics and microorganisms used in the study.

\subsection{Contois kinetic model}

Specific growth rate $\mu_{\max }$ and kinetic parameter $b$ coefficients were determined by using the data in Table 2 in the equation 16 . these kinetic parameters, $\mu_{\max }$ and $b$ were calculated from the intercept and the slope of the

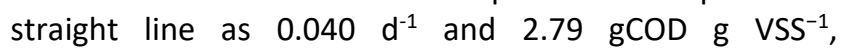
respectively.

Table 4. Calculated $\mathrm{k}_{(2) \mathrm{s}}$ values of the Grau second-order kinetic model

\begin{tabular}{ccccccc}
\hline $\boldsymbol{\theta}$ (HRT) day & $\mathbf{S}_{\mathbf{0}}(\mathbf{g} / \mathbf{I})$ & $\mathbf{S}(\mathbf{g} / \mathbf{I})$ & $\mathbf{X}_{\mathbf{0}}(\mathbf{g}$ VSS I-1) & $\mathbf{X}\left(\mathbf{g ~ V S S ~ ~ ^ { - 1 } )}\right.$ & $\mathbf{E}(\%)$ & $\mathbf{K}_{\mathbf{2 S}}=\mathbf{S}_{\mathbf{0}} / \mathbf{a} * \mathbf{X}$ \\
\hline 3 & 18,075 & 2,53 & 12,40 & 12,90 & 0,860 & 2,79 \\
\hline 2 & 17,980 & 3,42 & 12,43 & 12,70 & 0,810 & 2,81 \\
\hline 1 & 17,985 & 5,41 & 12,42 & 11,90 & 0,699 & 3,00 \\
\hline 0,5 & 17,990 & 10,31 & 12,44 & 9,32 & 0,427 & 3,84 \\
\hline 0,17 & 17,810 & 12,50 & 12,43 & 7,53 & 0,298 & 4,70 \\
\hline
\end{tabular}


Table 5. Comparison of kinetic constants in the Grau-second order model

\begin{tabular}{cccccc}
\hline Types of wastewater & Reactor & $\mathbf{a}$ & $\mathbf{b}$ & $\boldsymbol{k}_{\mathbf{2}} \mathbf{c}$ & References \\
\hline Pharmaceutical wastewater & hUASB & 0,503 & 0,9919 & 3,43 & This study \\
\hline High-strength wastewater & An-HBR & 0,517 & 0,838 & 0,53 & (Burman and Sinha, 2020) \\
\hline Textile dyeing wastewater & UASB & 0,197 & 1,422 & 0,418 & (Gnanapragasam et al., 2017) \\
\hline Simulated wastewater & MBBR & 0,562 & 1,095 & 0,337 & (Borghei and Hosseiny, 2002) \\
\hline Formaldehyde containing wastewater & UAFB & 0,64 & 9,36 & 3,2 & (Priya et al., 2009) \\
\hline Seafood wastewater & UASB & 0,27 & 1,009 & 1,3 & (Jijai et al., 2016) \\
\hline Synthetic wastewater & UASB & 0,558 & 1,043 & 0,8 & (Puspendu and Ghangrekar, \\
& & & & & 2008) \\
\hline Industrial wastewater & UASB & 0,583 & 2,023 & 0,163 & (Abtahi et al., 2013) \\
\hline
\end{tabular}

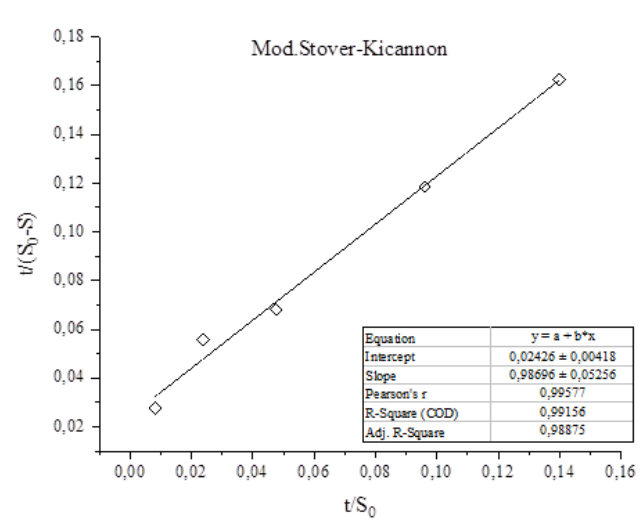

Figure 4. Modified Stover-Kincannon model plot for $\left(R_{\max }\right)$ and saturation constant $\left(K_{B}\right)$

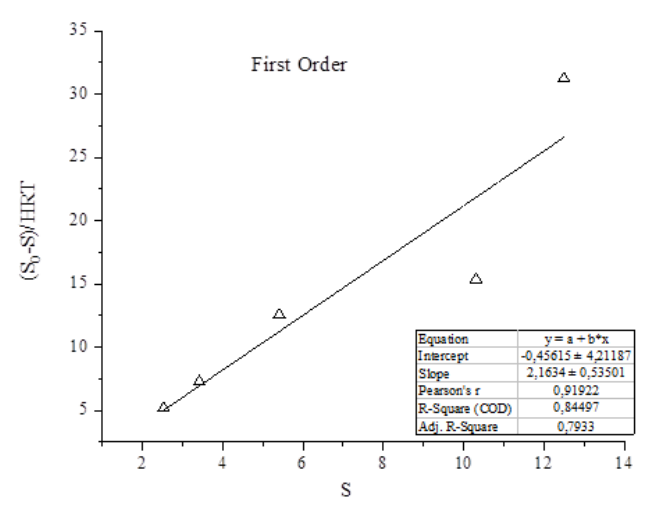

Figure 5. First order model plot for kinetic constant (k1)

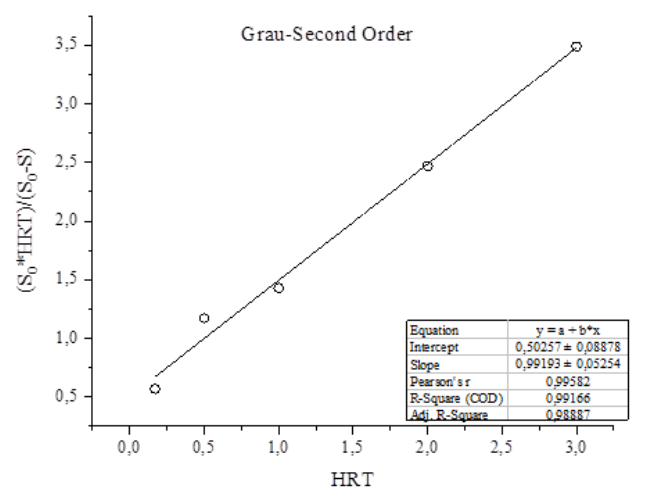

Figure 6. Grau second-order model for kinetic constants

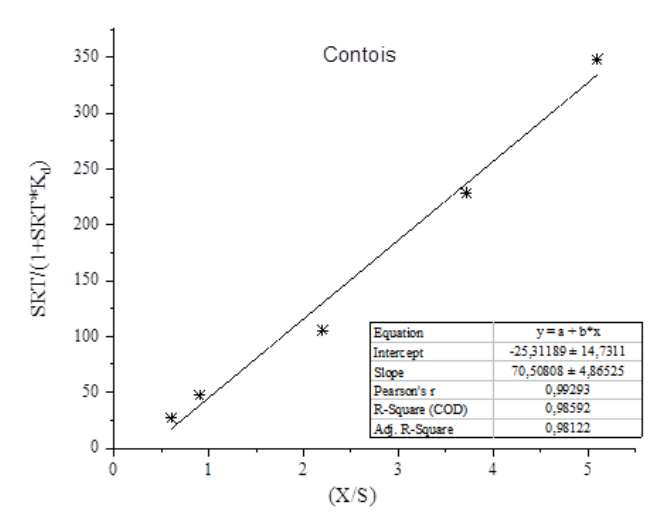

Figure 7. Contois model for kinetic constants

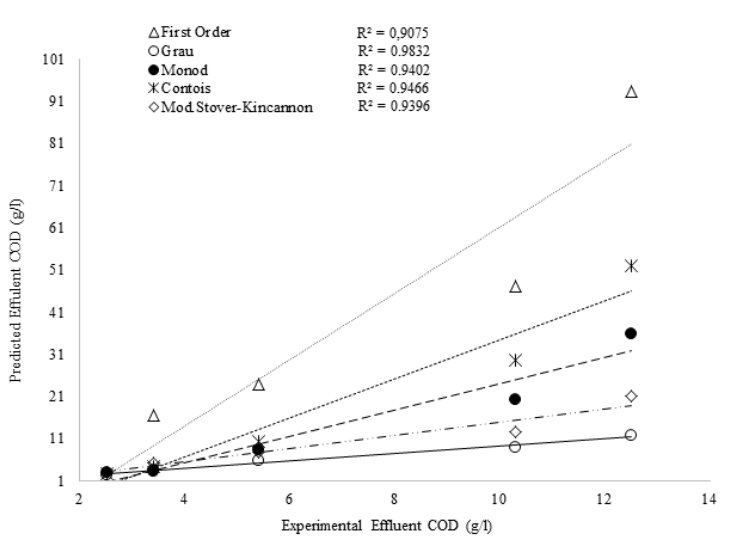

Figure 8. Comparison of predicted and experimental effluent COD 


\subsection{Prediction and validation}

Validity of the models is the results obtained from the experimental effluent COD values were compared with the predicted values obtained from the models. The highest correlation of the modelling was determined Grau secondorder ( $\left.R^{2}: 0.98\right)$ and Contois ( $\left.R^{2}: 0.99\right)$ kinetic models. But predicted values by models have different correlations. It could be think that predicted results are in good agreement with the experimental data in case of Grau second-order and Contois models Figure 8. The Monod, Mod.StoverKincannon and First Order models which have lower regression coefficient than others has not been suitable for predicting the COD values.

Among these, Modified Stover-Kicannon and Grau models gave the highest correlation coefficients, $99 \%$ and $99 \%$ respectively. The substrate removal rate constant $k_{2 s}$ was calculated using different conditions at steady-state conditions and were shown in Table 5 . As seen in the table, $k_{2 S}$ was determined $3,43 d^{-1}$ for hybrid UASB reactor. In the literature, kinetic studies conducted in UASB for the treatment of chlorinated ethane-containing wastewater indicated that this value varied between 1.12 and $7.53 \mathrm{~d}^{-1}$ (Basu and Asolekar, 2012). Figure 6 was plotted using the experimental data given in Table 2. The (a) and (b) values were calculated as 0.503 and 0.9919 respectively with the correlation coefficient $\left(R^{2}=0.991\right)$. In a literature study, these values $a$ and $b$ were found to be 0.197 and 1.42 respectively during the treatment of textile dyeing wastewater in the UASB reactor (Gnanapragasam et al., 2017). These values for UASB reactors is so close each other. Kinetic coefficients for Grau model at Different studies was illustrated in Table 6. Modified StoverKincannon is high correlation other model for this study also. By applying the Stover-Kincannon model which has high correlation, to the experimental studies, kinetic assessment was carried out. The value of $K_{B}$ can be calculated from the intercept of the straight line and $R_{\max }$ can be obtained from the slope line of Figure $4 . R_{\max }$ and $K_{B}$ were found to be $1,016\left(\mathrm{~g} \mathrm{l}^{-1} \mathrm{~d}\right)$ and $0.0247\left(\mathrm{~g} \mathrm{COD}^{-1} \mathrm{l}\right)$ respectively. It is noteworthy that the Stover-Kincannon model have much lower kinetic (saturation constant $\left(K_{B}\right)$ and maximum substrate consumption rate $\left(R_{\max }\right)$ than many studies in the literature. In studies conducted with toxic pharmaceutical wastewater, etc., such values are frequently encountered (Priya et al., 2009). In addition, although the Monod equation has a high correlation, $\mu_{\max }$ has a negative value. Figure 2 indicates negative Ks value with regression coefficient of 0.9904. Converti et al. (1999) reported that these constants can be attributed to the maximum degree of degradation of negative values. Since this issue could not be fully explained, the Monod equation and First order substrate removal kinetic equation were able not evaluated due to the relatively low correlation. Kinetic values of Grau model agree well with the values given in literature. As can be seen, applying Grau model's coefficients slightly lower values than reported in literature. Because wastewater contains a soluble substrate, the time for the substrate to hydrolyze is short. Chemical synthesis-based pharmaceutical wastewater includes important amount solvents, soluble substances, volatile fatty acids, heavy metals and toxic substances etc than other processes of pharmaceutical wastewater. Therefore, the substrate removal rate is a a little bit low. Studied with pharmaceutical wastewater, obtained coefficients from kinetic models may be change continously.

\section{Conclusion}

The Grau second-order model has given similar results in studies with wastewaters comparable to chemical synthesis wastewaters. In the literature, kinetic evaluations have been usually performed on the Stover-Kincannon model, in this study have a high correlation in the reactor also. The Grau second-order model for biofilm-suspended culture reactors seems more appropriate when the substrate removal efficiency is predicted in this type of wastewater containing highly dissolved organic matter.

\section{Acknowledgements}

This study was funded by Istanbul University-Cerrahpasa with the project number 24546 .

\section{Abbreviations}

$\mathrm{Q}$ : Inflow discharge to reactor $(\mathrm{L} / \mathrm{d})$

V: Reactor volume (L)

S: Influent substrate concentration

S: Effluent substrate concentration

$\mathrm{X}$ : Total biomass concentration in reactor (g VSS/L)

$\mathrm{X}_{0}$ : Influent biomass concentration (g VSS/L)

Xe: Effluent biomass concentration (g VSS/L)

$\Theta_{H}:$ Hydraulic retention time (d)

$\Theta_{c}$ : Solids retention time (d)

$\mathrm{Y}$ : yield coefficient (g VSS/g COD)

$\mathrm{K}_{\mathrm{d}}$ : Endogenous decay coefficient $\left(\mathrm{d}^{-1}\right)$

$\mu$ : Specific growth rate $\left(\mathrm{d}^{-1}\right)$

$\mu_{\max }$ : Maximum specific growth rate $\left(\mathrm{d}^{-1}\right)$

Ks: Half-velocity constant (g COD/L)

$\mathrm{K}$ : Maximum substrate consumption rate in microorganis mass ( $\mathrm{g}$ COD/g VSS.d)

B: Synthetic constant of Contois model (g COD/g VSS)

$k_{2}(\mathrm{~S})$ :Substrate removal rate of second-Order Grau model, Monod model $\left(d^{-1}\right)$

$\alpha$ : Equals $\mathrm{S}_{0} / \mathrm{K}_{2}(\mathrm{~S}) \cdot \mathrm{X}$ (g COD.d/g VSS)

$b$ : Without unit

$K_{B}$ : Saturation constant (g COD/L.d)

$R_{\max }$ : Maximum substrate consumption rate (g COD/L.d)

SSUR: Spesifik substrat Utilization rate (kgCOD/kgVSS.day)

SUR: Substrat utilization rate (kgCOD/kgVSS.day)

$k_{1}$ : Kinetic constant for first order substrat removal model (gCOD/gSS.day) 


\section{References}

Abtahi S.M., Amin M.M., Nateghi R., Vosoogh A. and Dooranmahalleh M.G. (2013), Prediction of effluent COD concentration of UASB reactor using kinetic models of monod, contois, second-order Grau and modified Stover-kincannon, International Journal of Environmental Health Engineering, 2(1), 12.

Acharya B.K., Pathaka H., Mohana S., Shouche Y., Singh V. and Madamwar D. (2011), Kinetic modelling and microbial community assessment of anaerobic biphasic fixed film bioreactor treating distillery spent wash, Water Research, 45(14), 4248-4259.

Ahn J.H. and Forster C.F.A. (2002), Comparison mesophilic and thermophilic anaerobic upflow filter treating paper-pulp liquors, Process Biochemistry, 38(2), 256-261.

Alavi N.A., Mirzai1 M., Sajadi A.A. and Hasanian H. (2016), Biokinetic modeling for aerobic treatment of aqueous phase of oil-water emulsion, Bioscience Biotechnology Research Communications, 9(4), 625-632.

Andualem M., Seyoum L. and Karoli N.N. (2017), Kinetic analysis of anaerobic sequencing batch reactor for the treatment of tannery wastewater, African Journal of Environmental Science and Technology, 11(6), 339-348.

APHA-AWWA. (2017.) Standard methods for water and wastewater. $23^{\text {th }}$ ed. American Public Health Assoc/American Water Works Assoc. Washington DC, USA.

Athanasoulia E., Melidis P., Aivasidis A. (2012), Optimization of biogas production from waste activated sludge through serial digestion, Renewable Energy, 30(47), 147-151.

Basu D. and Asolekar SR. (2012), Evaluation of substrate removal kinetics for UASB reactors treating chlorinated ethanes, Environmental Science and Pollution Research, 19(6), 24192427.

Berardino S.D., Costa S. and Converti A. (2000), Semi-continuous anaerobic digestion of a food industry wastewater in an anaerobic filter, Bioresource Technology, 71(3), 261-266.

Bhunia P. and Ghangrekar M.M. (2008), Analysis, evaluation, and optimization of kinetic parameters for performance appraisal and design of UASB reactors, Bioresource Technology, 99, 2132-2140.

Borghei S.M. and Hosseiny S.H. (2002), Modeling of organic removal in a moving bed biofilm reactor (MBBR). Scientica Iranica, 9, 53-58.

Boroski M., Rodrigues A.C., Garcia J.C., Sampaio L.C., Nozaki J. and Hioka N. (2009), Combined electrocoagulation and $\mathrm{TiO}_{2}$ photoassisted treatment applied to wastewater effluents from pharmaceutical and cosmetic industries, Journal of Hazardous Materials 162, 448-454.

Burman I. and Alok S. (2020), Performance evaluation and substrate removal kinetics in an up-flow anaerobic hybrid membrane bioreactor treating simulated high-strength wastewater, Environmental Technology, 41(3), 309-321.

Chandak S., Ghosh P.K. and Gogate P.R. (2020), Treatment of real pharmaceutical wastewater using different processes based on ultrasound in combination with oxidants, Process Safety and Environmental Protection, 137, 149-157.

Chen Z., Wang H., Ren N., Cui M., Nie S. and Hu D. (2011) Simultaneous removal and evaluation of organic substrates and $\mathrm{NH}_{3}-\mathrm{N}$ by a novel combined process in treating chemical synthesis- based pharmaceutical wastewater, Journal of Hazardous Materials, 197(128), 49-59.
Contois D.E. (1959), Kinetics of Bacterial Growth: Relationship between Population Density and Specific Growth Rate of Continuous Cultures, Journal of General Microbiology, 21, 40-50.

Farhadi S., Aminzadeh B., Torabian A., Katibikamal V. and Fard M.A. (2012), Comparison of COD removal from pharmaceutical wastewater by electrocoagulation, photoelectrocoagulation, peroxi-electrocoagulation and peroxi-photoelectrocoagulation processes, Journal of Hazardous Materials, 219-220, 35-42.

Faridnasr M., Ghanbari B. and Sassani A. (2016), Optimization of the moving-bed biofilm sequencing batch reactor (MBSBR) to control aeration time by kinetic computational modeling: Simulated sugar-industry wastewater treatment, Bioresource Technology, 208, 149-160.

Fernândez J.M., Omil F., Mendez R. and Lema J. (2001), Anaerobic treatment of fibreboard manufacturing wastewaters in a pilot scale hybrid USBF reactor, Water Research, 35, 4150-4158.

Gnanapragasam G., Arutchelvan V., Soundari L. and Maneeshkumar C.S. (2017), Evaluation of kinetic models for tearing textile dyeing wastewater using UASB reactor, Journal of Biotechnology and Biochemistry, 3(4), 57-65.

Grau P., Dohanyas M. and Chudoba J. (1975), Kinetic of multicomponent substrate removal by activated sludge, Water Research, 9, 637-642.

Hwang S.H., Hansen C.L. and Stevens D.K. (1992), Biokinetics of an upflow anaerobic sludge blanket reactor treating whey permeate, Bioresource Technology, 41(3), 223-230.

Jantsch T.G., Angelidaki I., Schmidt J.E., Brañade H. and Ahring B.K. (2002), Anaerobic biodegradation of spent sulphide liquor in an UASB reactor, Bioresource Technology, 84(1), 15-20.

Jijai S., Siripatana C., Sompong O. and Ismail N. (2016), Kinetic models for prediction of COD effluent from upflow anaerobic sludge blanket (UASB) reactor for cannery seafood wastewater treatment, Jurnal Teknologi, 78(5-6), 93-99.

Kordkandi S.A. and Berardi L. (2015), Comparing new perspective of hybrid approach and conventional kinetic modelling techniques of a submerged biofilm reactor performance, Biochemical Engineering Journal, 103, 170-176.

Mengcheng Q., Linyan Y., Xingkui C., Kai L., Weibo X., Yejin L., Huihui Z., Guomin C., Xiaohong G. and Genxiang S. (2020), The treatment of veterinary antibiotics in swine wastewater by biodegradation and Fenton-like oxidatio, Science of the Total Environment, 710, 36299.

Monod J. (1949), The growth of bacterial cultures, Annual Review of Microbiology, 3, 371-394.

Noroozi A., Farhadian M. and Solaimanynazar A. (2014), Kinetic coefficients for the domestic wastewater treatment using hybrid activated sludge process, Desalination and Water Treatment, 57, 4439-4446.

Oktem Y.A. (2004), Comparison of system performances of single and two phase anaerobic digestion treating a chemical synthesis-based pharmaceutical wastewater, Ph.D. Thesis, Department of Environmental Engineering, Istanbul Technical University.

Oktem YA., Ince O., Sallis P., Donnelly T. and Kasapgil Ince B. (2007), Anaerobic treatment of a chemical synthesis-based pharmaceutical wastewater in a hybrid upflow anaerobic sludge blanket reactor, Bioresource Technology, 99, 1089-1096. 
Pandian M., NGO H.H. and Pazhaniappan S. (2011), Substrate removal kinetics of an anaerobic hybrid reactor treating pharmaceutical wastewater, Journal of Water Sustainability, 3, 301-312.

Priya K.R., Sandhya S. and Swaminathan K. (2009), K. Kinetic analysis of treatment of formaldehyde containing wastewater in UAFB reactor, Chemical Engineering Journal, 148(2/3), 212-216.

Saberia R., Hassanib A.H., Abedib M.S., Ardeshira A.T. and Mozaffaric A. (2017), Kinetics of aerobic biodegradation of organic pollutants in moving bed biological reactor (MBBR), Desalination and Water Treatment, 98, 31-36.

Sakumoto A. and Miyata T. (1984), Treatment of waste water by a combined technique of radiation and conventional method, Radiation Physics and Chemistry (1977), 24(1), 99-115.

Sandhya S. and Swaminathan K. (2006), Kinetic analysis of treatment of textile wastewater in hybrid column upflow anaerobic fixed bed reactor, Chemical Engineering Journal, 122, 87-92.

Senturk E., Ince M. and Onkal E.G. (2013), Assesment of kinetic parameters for thermophilic anaerobic contact reactor treating food-processing wastewater, International Journal of Environmental Research, 7(2), 293-302.

Shivayogimath C.B. and Ramanujam T.K. (1999), Treatment of distillery spentwash by hybrid UASB reactor, Bioprocess Engineering, 21, 255-259.

Singh R.P. and Ohja C.S.J. (2002), Simulation of a UASB reactor performance treating whey permeate wastewater: Water and wastewater perspectives of developing countries, Amatya Publishers, New Delhi, India.

Stover E.L.and Kincannon D.F. (1982), Rotating biological contactor scale-up and design, $1^{\text {st }}$ International Conference on Fixed Film Biological Processes Kings Island, Ohio, USA, 1-12.

Stronach S.M., Rudd. T and Lester J.N. (1986), Anaerobic digestion process in industrial wastewater Treatment, Springer Verlag, Berlin, Germany.

Tineo P.A.G., Hinojosa U.D., Mirquez L.R.D., Escalante E.R.M., Moroyoqui P.G., Mercado R.G.U. and Palacios D.S. (2020), Performance improvement of an integrated anaerobicaerobic hybrid reactor for the treatment of swine wastewater, Journal of Water Process Engineering, 34, 101164.

To H.T., Wu H., Song B., Liu S-S., Bhardwaj A. and Wong J.W.C. (2020), Food waste leachate treatment using an Upflow Anaerobic Sludge Bed (UASB): Effect of conductive material dosage under low and high organic loads, Bioresource Technology, 304122738

Tomar S. and Gupta S.K. (2015), Investigating the process kinetics and nitrogen gas production in anammox hybrid reactor with special emphasis on the role of filter media, International Journal of Environmental and Ecological Engineering, 9(9), 1091-1097.

Wang J., Yan J. and Xu W. (2015), Treatment of dyeing wastewater by MIC anaerobic reactor, Biochemical Engineering Journal, 101, 179-184.

Yu H., Wilson F. and Tay J.H. (1983), Kinetic analysis of an aerobic filter treating soybean wastewater. Water Research, 32, 3341-3352.

Yue F., Wang Q., Duan J-L., Li X-Y., Ma J-Y., Wu L., Han Y., Liu X-Y., Zhang Y-B. and Yuan X-Z. (2020), Attachment and adhesion force between biogas bubbles and anaerobic granular sludge in the up-flow anaerobic sludge blanket, Water Research, 171,115458 .

Zhang L. (2020) Advanced treatment of oilfield wastewater by a combination of DAF, yeast bioreactor, UASB, and BAF processes, Separation Science and Technology, 1711411.

Zhou X., Zhanga Z. and Lia Y. (2017), Four-stage biofilm anaerobicanoxic-oxic-oxic system for strengthening the biological treatment of coking wastewater: COD removal behaviors and biokinetic modeling, RSC Advances, 7, 23714-23726. 